\title{
Euvolemic hyponatremia in cancer patients. Report of the Hyponatremia Registry: an observational multicenter international study
}

\author{
Volker Burst $^{1}$ (D) - Franziska Grundmann ${ }^{1}$ - Torsten Kubacki ${ }^{1}$ - Arthur Greenberg ${ }^{2}$. \\ Despina Rudolf $^{3} \cdot$ Abdulla Salahudeen $^{4} \cdot$ Joseph Verbalis $^{5} \cdot$ Christian Grohé $^{6}$
}

Received: 14 June 2016 / Accepted: 10 February 2017 / Published online: 2 March 2017

(C) The Author(s) 2017. This article is published with open access at Springerlink.com

\begin{abstract}
Purpose Hyponatremia secondary to SIADH is frequent in cancer patients and potentially deleterious. The aim of this sub-analysis of the Hyponatremia Registry database is to analyze current diagnostic and therapeutic management practices in cancer patients with SIADH.

Methods We analyzed 358 cancer patients who had serum sodium concentration $\left(\left[\mathrm{Na}^{+}\right]\right) \leq 130 \mathrm{mEq} / \mathrm{L}$ and a clinical diagnosis of SIADH from 225 sites in the USA and EU.

Results Precise diagnostic testing was performed in only $46 \%$. Almost $12 \%$ of all patients did not receive any hyponatremia treatment. The most frequent therapies were fluid restriction $(20 \%)$, isotonic saline (14\%), fluid restriction/isotonic saline $(7 \%)$, tolvaptan $(8 \%)$, and salt tablets $(7 \%)$. Hypertonic saline was used in less than $3 \%$. Tolvaptan produced the greatest median rate of $\left[\mathrm{Na}^{+}\right]$change (IQR) $(3.0(4.7) \mathrm{mEq} / \mathrm{L} /$ day),
\end{abstract}

Electronic supplementary material The online version of this article (doi:10.1007/s00520-017-3638-3) contains supplementary material, which is available to authorized users.

Volker Burst

volker.burst@uk-koeln.de

1 Department II of Internal Medicine and Center for Molecular Medicine, University of Cologne, Cologne, Kerpener Str. 62, 50937 Cologne, Germany

2 Duke University Medical Center, Durham, NC, USA

3 Otsuka Pharma GmbH, Frankfurt, Germany

4 Renal Section, Department of Internal Medicine, University of Texas M.D. Anderson Cancer Ctr, Houston, TX, USA

5 Georgetown University Medical Center, Washington, DC, USA

6 Department of Respiratory Diseases, Ev. Lungenklinik Berlin, Berlin, Germany followed by hypertonic saline (2.0(7.0) $\mathrm{mEq} / \mathrm{L} / \mathrm{day})$, and fluid restriction/isotonic saline (1.9(3.2) $\mathrm{mEq} / \mathrm{L} /$ day). Both fluid restriction and isotonic saline monotherapies were significantly less effective $(0.8(2.0) \mathrm{mEq} / \mathrm{L} /$ day and $1.3(3.0) \mathrm{mEq} / \mathrm{L} /$ day, respectively) and were associated with clinically relevant rates of treatment failure. Only $46 \%$ of patients were discharged with $\left[\mathrm{Na}^{+}\right] \geq 130 \mathrm{mEq} / \mathrm{L}$. Overly rapid correction of hyponatremia occurred in $11.7 \%$.

Conclusions Although essential for successful hyponatremia management, appropriate diagnostic testing is not routinely performed in current practice. The most frequently employed monotherapies were often ineffective and sometimes even aggravated hyponatremia. Tolvaptan was used less often but showed significantly greater effectiveness. Despite clear evidence that hyponatremia is associated with poor outcome in oncology patients, most patients were discharged still hyponatremic. Further studies are needed to assess the beneficial impact of hyponatremia correction with effective therapies.

Keywords Hyponatremia $\cdot$ Syndrome of inappropriate antidiuretic hormone secretion (SIADH) · Cancer · Fluid restriction $\cdot$ Isotonic saline $\cdot$ Tolvaptan

\section{Introduction}

Hyponatremia is frequently observed in cancer patients and can be explained by malignant disease itself, concomitant comorbidities, physical stress (e.g., pain), or medication [1-3]. In hospitalized cancer patients, hyponatremia is associated with increased mortality and length of hospital stay, and higher costs [4-10]. It is widely accepted that the syndrome of inappropriate secretion of antidiuretic hormone (SIADH) due to ectopic release of vasopressin accounts for the majority of cases [11]. However, drugs including chemotherapies as 
well as targeted therapies [12], hypo- or hypervolemia, as well as other less frequent disorders such as adrenal insufficiency, myxedema, etc. must be ruled out as possible alternative causes [13-15]. Diagnostic work-up is often viewed as complex, and treatment is considered cumbersome and potentially dangerous. However, despite the urgent need for better education on how to approach the hyponatremic patient [16], no evidence-based guideline for hyponatremia management specific to cancer patients is available. Current management strategies are not well characterized.

The multinational Hyponatremia Registry (NCT01240668) assessed the current state of treatment for euvolemic and hypervolemic hyponatremia in real-world hospital settings. This report focuses on the subgroup of patients with cancer and SIADH with the aim to determine which diagnostic and treatment modalities are employed, how effective they are, and how rapidly and reliably they result in an increase in serum $\left[\mathrm{Na}^{+}\right]$.

\section{Patients and methods}

\section{Study plan}

The study design has been described previously in detail [17, 18]. In brief, patients with euvolemic or hypervolemic hyponatremia were enrolled from 146 US sites and 79 EU sites. For the present publication, only patients initially assessed as clinically euvolemic were analyzed. The study was exclusively observational; no standardized diagnostic or treatment protocols were imposed.

\section{Inclusion and exclusion criteria}

Only patients with clinically meaningful hyponatremia $\left(\left[\mathrm{Na}^{+}\right] \leq 130 \mathrm{mEq} / \mathrm{L}\right)$ and physician-diagnosed euvolemia were enrolled. In a pre-specified adjudication process [17], individuals whose medical file reports were inconsistent with the diagnosis of euvolemia were excluded.

\section{Statistical methods}

Mild hyponatremia was defined as $130 \mathrm{mEq} / \mathrm{L} \geq\left[\mathrm{Na}^{+}\right]>125$ $\mathrm{mEq} / \mathrm{L}$, moderate hyponatremia as $125 \mathrm{mEq} / \mathrm{L} \geq\left[\mathrm{Na}^{+}\right] \geq 120$ $\mathrm{mEq} / \mathrm{L}$, and severe hyponatremia as $\left[\mathrm{Na}^{+}\right]<120 \mathrm{mEq} / \mathrm{L}$. Overly rapid correction of $\left[\mathrm{Na}^{+}\right]$was defined as an increase $>12 \mathrm{mEq} / \mathrm{L}$ in any $24-\mathrm{h}$ interval or $>18 \mathrm{mEq} / \mathrm{L}$ in any $48-\mathrm{h}$ interval. Rate of change of $\left[\mathrm{Na}^{+}\right]$was calculated as the total increment in $\left[\mathrm{Na}^{+}\right]$during the treatment divided by the number of treatment days.

Categorical variables were compared using a chi-square test. In the case of more than two comparison groups, an overall chi-square test was done before performing individual pairwise chi-square tests

Nonparametric analysis was performed for continuous variables. In case of more than two comparison groups, a Kruskal-Wallis test was done to generate an overall test for equality of medians followed by pairwise group comparisons. For comparisons of only two groups, medians were compared using the Wilcoxon Rank Sum Test. $P$ values were not adjusted for multiple comparisons.

\section{Results}

Of the 5028 patients enrolled between September 2010 and February 2013, 2847 patients had euvolemic hyponatremia, and 586 of these $(21 \%)$ were cancer-related. After adjudication, 1597 were confirmed to have euvolemic hyponatremia, SIADH being the most likely cause in 1524 (95\%). Two hundred twenty-eight cancer patients initially labeled euvolemic were excluded during adjudication. The 358 remaining patients diagnosed as cancer-related SIADH constitute the primary analysis group. The 1166 SIADH patients without a history of cancer served as comparison group.

The most frequently reported types of cancer were lung cancer $(53.4 \%)$, tumors of the pituitary $(5.5 \%)$, brain $(5.3 \%)$, head and neck $(4.2 \%)$, and breast $(3.4 \%)$ (Supplemental Table 1). Patient demographics and clinical characteristics are shown in Table 1 . In contrast to the non-cancer group, cancer-related SIADH patients were more likely to be male and significantly younger. Hyponatremia was present at hospital admission in more than $80 \%$ and prior hyponatremia episodes had been reported in more than $30 \%$. Generalists or oncologists were in charge of approximately $70 \%$ of all cases of cancerrelated SIADH and a hyponatremia expert, i.e., endocrinologist or nephrologist, was consulted in only $42.7 \%$. Although the median serum $\left[\mathrm{Na}^{+}\right]$at the time of diagnosis was the same in both groups $(124 \mathrm{mEq} / \mathrm{L})$, significantly more cases of severe hyponatremia were found in the cancer group.

Appropriate diagnostic testing for SIADH requires the assessment of the so-called Schwartz-Bartter criteria, i.e., serum and urinary osmolality and urinary sodium [15, 19]. In $13 \%$ of all cancer-related SIADH patients, none of these tests was obtained; the complete trio was assessed in only $46 \%$. Diagnostic rigor was even worse in the subgroups comprising lung cancer patients and SCLC patients with all tests reported in 41 and $36 \%$, respectively (Supplemental Table 2).

While almost all cancer patients with severe hyponatremia $(99.1 \%)$ received active hyponatremia treatment, only 91 and $79 \%$ of patients with moderate or mild hyponatremia, 
Table 1 Baseline demographic and clinical characteristics for the primary analysis group, cancer subgroups, and non-cancer-related SIADH group

All cancer-related Lung cancer patients $\quad$ SCLC patients $\quad$ Non-cancer-related

SIADH (\%) $n=358 \quad(\%) n=191 \quad$ (\%) $n=90 \quad$ SIADH (\%) $n=1166$

Age distribution, $n(\%)^{\mathrm{a}}$

\begin{tabular}{|c|c|c|c|c|}
\hline$\leq 50$ years & $35(9.8)$ & $11(5.8)$ & $3(3.3)$ & $151(13.0)$ \\
\hline $51-64$ years & $125(34.9)$ & $76(39.8)$ & $46(51.1)$ & $248(21.3)$ \\
\hline $65-74$ years & $106(29.6)$ & $61(31.9)$ & $27(30.0)$ & $233(20.0)$ \\
\hline$\geq 75$ years & $92(25.7)$ & $43(22.5)$ & $14(15.6)$ & $534(45.8)$ \\
\hline Men, $n(\%)^{\mathrm{a}}$ & $186(52)$ & $100(52.4)$ & $43(47.8)$ & $509(43.7)$ \\
\hline \multicolumn{5}{|l|}{ Prior hyponatremia, $n(\%)^{\mathrm{b}}$} \\
\hline Yes & $109(30.4)$ & $68(35.6)$ & $41(45.6)$ & $298(25.6)$ \\
\hline No & $160(44.7)$ & $80(41.9)$ & $35(38.9)$ & $527(45.2)$ \\
\hline Unknown & $89(24.9)$ & $43(22.5)$ & $14(15.6)$ & $341(29.2)$ \\
\hline \multicolumn{5}{|l|}{ Hyponatremia at admission, $n(\%)$} \\
\hline Yes & $288(80.4)$ & $166(86.9)$ & $82(91.1)$ & $964(82.7)$ \\
\hline No & $65(18.2)$ & $24(12.6)$ & $7(7.8)$ & $188(16.1)$ \\
\hline Unknown & $5(1.4)$ & $1(0.5)$ & $1(1.1)$ & $14(1.2)$ \\
\hline \multicolumn{5}{|l|}{ Primary physician specialty, $n(\%)^{\mathrm{a}}$} \\
\hline Generalist & $183(51.1)$ & $105(55.0)$ & $40(44.4)$ & $761(65.3)$ \\
\hline Oncologist & $67(18.7)$ & $41(21.5)$ & $31(34.4)$ & $25(2.1)$ \\
\hline Endocrinologist & $23(6.4)$ & $10(5.2)$ & $5(5.6)$ & $83(7.1)$ \\
\hline Nephrologist & $15(4.2)$ & $7(3.7)$ & $2(2.2)$ & $67(5.7)$ \\
\hline Cardiologist & $10(2.8)$ & $6(3.1)$ & $2(2.2)$ & $39(3.3)$ \\
\hline Other & $60(16.8)$ & $22(11.5)$ & $10(11.1)$ & $190(16.3)$ \\
\hline \multicolumn{5}{|l|}{ Endocrinologist or nephrologist consulted, $n(\%)^{\mathrm{c}}$} \\
\hline No & $203(56.7)$ & $115(60.2)$ & $53(58.9)$ & $636(54.5)$ \\
\hline Yes & $153(42.7)$ & $75(39.3)$ & $37(41.1)$ & $530(45.5)$ \\
\hline Median initial $\left[\mathrm{Na}^{+}\right](\mathrm{IQR}), \mathrm{mEq} / \mathrm{L}$ & $124(10)$ & $122(10)$ & $121(10)$ & $124(8)$ \\
\hline Median discharge $\left[\mathrm{Na}^{+}\right](\mathrm{IQR}), \mathrm{mEq} / \mathrm{L}^{\mathrm{a}}$ & $130(7.0)$ & $130(7.0)$ & $131(8.0)$ & $132(7.0)$ \\
\hline$\left[\mathrm{Na}^{+}\right]<120 \mathrm{mEq} / \mathrm{L}, n(\%)$ & $108(30.2)$ & $71(37.2)$ & $41(45.6)$ & $299(25.6)$ \\
\hline Median initial creatinine (IQR), mg/dL ${ }^{\mathrm{a}}$ & $0.67(0.3)$ & $0.62(0.3)$ & $0.61(0.2)$ & $0.73(0.3)$ \\
\hline Median initial urine $\left[\mathrm{Na}^{+}\right]$(IQR), $\mathrm{mEq} / \mathrm{L}$ & $76(63.5)$ & $76.5(63.0)$ & $72.0(70.0)$ & $71.5(60)$ \\
\hline Median initial urine osmolality (IQR), $\mathrm{mOsm} / \mathrm{kg}^{\mathrm{a}}$ & $440(266)$ & $466(252)$ & $437(279)$ & $390(255)$ \\
\hline Median initial uric acid (IQR), mg/dL & $2.8(1.7)$ & $2.8(1.2)$ & $2.3(1.1)$ & $2.8(1.8)$ \\
\hline
\end{tabular}

$B U N$ blood urea nitrogen, $\left[\mathrm{Na}^{+}\right]$sodium concentration, $I Q R$ interquartile range

${ }^{\text {a }}$ Cancer vs. non-cancer: $P<0.01$

${ }^{\mathrm{b}}$ Hyponatremia during previous hospital admission in prior 12 months

${ }^{\mathrm{c}}$ Hyponatremia specialist defined as nephrologist or endocrinologist

respectively, were treated. The five most common active therapies in the cancer-related SIADH group were fluid restriction (FR, 20.1\%), isotonic saline (NS, 13.5\%), tolvaptan (7.9\%), salt tablets (ST, 6.5\%), and FR + NS (6.5\%). Sixty percent of all treatment episodes and $74 \%$ of all initial episodes consisted of a monotherapy. Hypertonic saline (HS) was used in only $2.2 \%$ overall and in $2.7 \%$ of cancer patients with severe hyponatremia. Demeclocycline was prescribed in $2.3 \%$, $0.3 \%$ (2) were prescribed conivaptan, and $0.5 \%$ (4) patients received urea, 3 of which received it in combination with another therapy. Stopping a medication that may induce
SIADH could also be considered an active treatment; of the patients who received no other active hyponatremia therapy, $44 \%$ were receiving a potentially hyponatremia-inducing medication (opiates $77 \%$, antidepressants $16 \%$, antiepileptics $2 \%$ ), which was discontinued in $21 \%$. Tolvaptan was chosen relatively more often in lung cancer $(7.9 \%)$ and in particular SCLC patients (10.3\%) than in the non-cancer group (6.2\%) while FR was used less often in cancer patients than in noncancer patients (Fig. 1).

With a median rate of $\left[\mathrm{Na}^{+}\right]$change (interquartile range, IQR) of $3.0(4.7) \mathrm{mEq} / \mathrm{L} /$ day and a median $\left[\mathrm{Na}^{+}\right]$increase of 

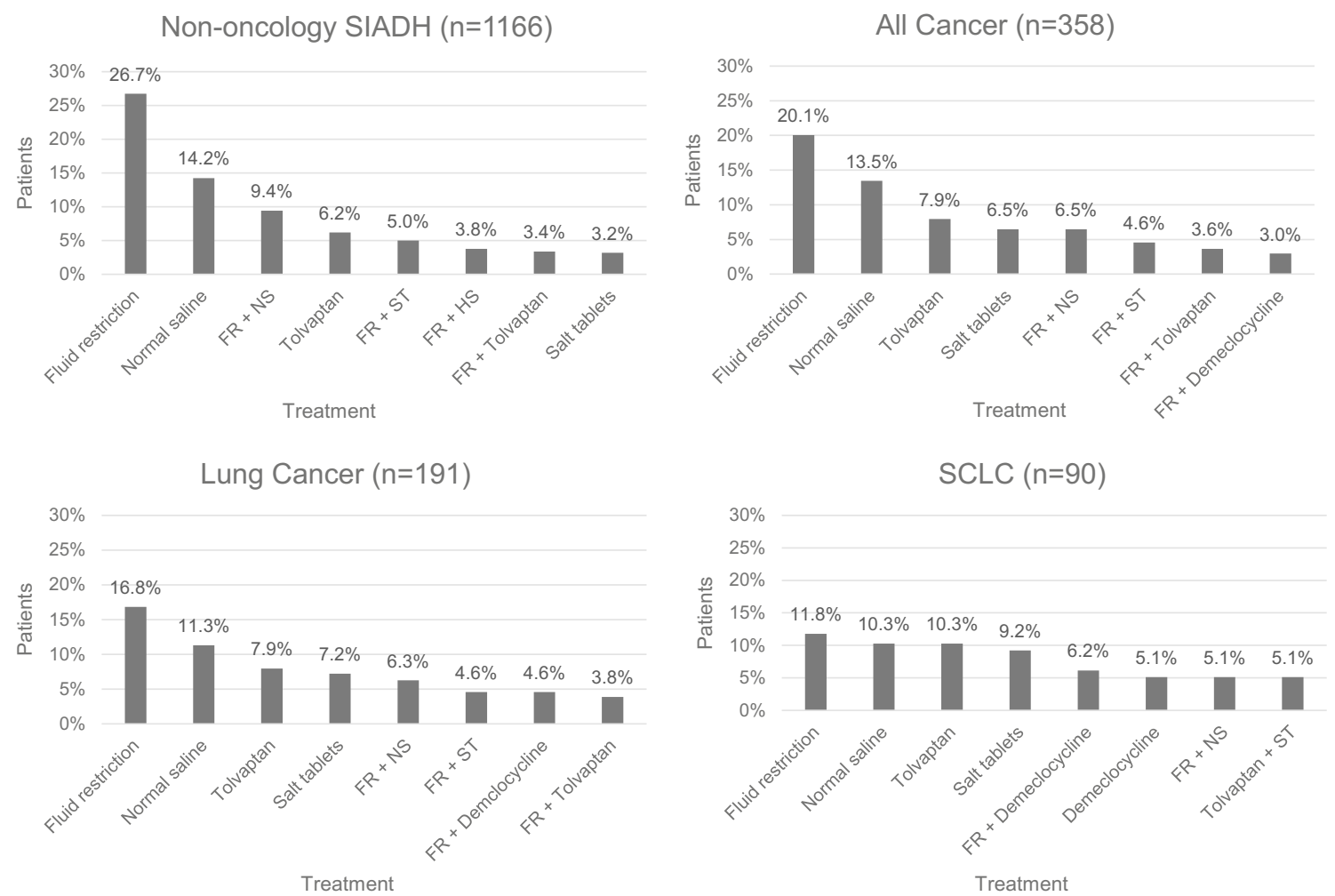

Fig. 1 Most frequently chosen therapies in actively treated patients in the primary analysis group and subgroups

4.0(8.0) $\mathrm{mEq} / \mathrm{L}$ within the first $24 \mathrm{~h}$ after treatment initiation, tolvaptan produced the most pronounced effect $(P<0.05$ for all comparisons except vs. HS; Table 2). Rates of change in the two conivaptan patients were 3.7 and $11 \mathrm{mEq} / \mathrm{L} / \mathrm{day}$, similar to tolvaptan. HS and FR + NS were equally effective (2.0 (7.0) and 1.9 (3.2) $\mathrm{mEq} / \mathrm{L} /$ day, respectively). FR and NS alone were considerably less effective $(0.8(2.0)$ and $1.3(3.0) \mathrm{mEq} / \mathrm{L} /$ day, respectively) while no treatment, salt tablets, and demeclocycline were ineffective $(0.1(0.7), 0.1(2.0)$, and $0.0(2.3) \mathrm{mEq} / \mathrm{L} / \mathrm{d}$, respectively). In patients with severe hyponatremia, HS showed the greatest median rate of change $(8.0(6.4) \mathrm{mEq} / \mathrm{L} / \mathrm{day})$, followed by tolvaptan (3.3 (3.9) $\mathrm{mEq} / \mathrm{L} /$ day), FR + NS (2.3 (3.0) mEq/ $\mathrm{L} /$ day), NS (2.0 (2.0) $\mathrm{mEq} / \mathrm{L} /$ day), and FR $(1.3(2.5) \mathrm{mEq} / \mathrm{L} /$ day). Regardless of the therapy chosen, the rate of $\left[\mathrm{Na}^{+}\right]$change increased with lower baseline serum $\left[\mathrm{Na}^{+}\right]$. Tolvaptan elicited an equivalent rate of change in both cancer and non-cancer groups. In contrast, for all other therapies, the effectiveness was superior in the non-cancer group.

Success and failure to control hyponatremia was assessed categorically by analyzing the rate of reaching several clinically relevant correction benchmarks (Table 3): aggravation $(\Delta$ $\left.\left[\mathrm{Na}^{+}\right]>-2 \mathrm{mEq} / \mathrm{L}\right)$, ineffectiveness $\left(\Delta\left[\mathrm{Na}^{+}\right]\right.$within $\pm 2 \mathrm{mEq} /$ $\mathrm{L})$, and clinically relevant effectiveness $\left(\Delta\left[\mathrm{Na}^{+}\right] \geq 5 \mathrm{mEq} / \mathrm{L}\right.$, achievement of $\left[\mathrm{Na}^{+}\right]>130 \mathrm{mEq} / \mathrm{L}$, normalization of $\left[\mathrm{Na}^{+}\right]$ $(\geq 135 \mathrm{mEq} / \mathrm{L}$ ). The pre-defined limits used as benchmark goals were chosen based on clinical expertise. Tolvaptan was significantly ( $P<0.01$ for most pairwise comparisons) more successful than any other treatment with regard to these correction benchmarks. A $\left[\mathrm{Na}^{+}\right]>130 \mathrm{mEq} / \mathrm{L}$ and normalization of $\left[\mathrm{Na}^{+}\right]$ were achieved in more than 73 and $39 \%$ of tolvaptan treatment episodes, respectively. Moreover, a clinically meaningful increase of $\left[\mathrm{Na}^{+}\right]$of $\geq 5 \mathrm{mEq} / \mathrm{L}$ was observed in almost $79 \%$. For any other treatment, success rates were about half as good at best ( $41 \%$ for a $\left.\mathrm{Na}^{+}\right]$increase of $\geq 5 \mathrm{mEq} / \mathrm{L}$ with $\mathrm{HS},<35 \%$ for all other therapies). Conversely, tolvaptan showed a more than $50 \%$ lower rate of correction failure (defined by the combined benchmark aggravation and ineffectiveness) compared to any other therapy with less than $15 \%$. The highest failure rate was reported for no therapy (68\%), followed by salt tablets $(54 \%)$, demeclocycline $(52 \%)$, NS (47\%), and FR (44\%). With tolvaptan, the results were almost identical in both the cancer and the non-cancer group, while all other therapies seemed to work better in non-cancer patients. Of note, the measurement of the Schwartz-Bartter criteria had no impact on the correction benchmark effectiveness $(P=0.50)$.

With better effectiveness came also higher rates of overcorrection with tolvaptan (14\%) and HS (16\%); significantly fewer cases of overcorrection occurred with the other therapies. Overall (monotherapies and combination therapies together), overly rapid correction was reported in 42 patients (11.7\%); in 29 of these cases, tolvaptan was employed and 11 patients received HS. No cases of osmotic demyelination syndrome were reported in the Hyponatremia Registry. No severe adverse reactions were reported with the use of vaptans.

Given the better efficacy of tolvaptan and HS in individual treatment episodes, data were pooled and examined to 
Table 2 Response to most frequently utilized therapies, hypertonic saline and demeclocycline for all therapy episodes in cancer-related and noncancer-related SIADH (all patients and patients with severe hyponatremia)

\begin{tabular}{|c|c|c|c|c|c|c|c|c|}
\hline \multirow[b]{2}{*}{ Treatment } & \multirow[b]{2}{*}{ Patient subgroup } & \multicolumn{4}{|c|}{$\left[\mathrm{Na}^{+}\right]<130 \mathrm{mEq} / \mathrm{L}$} & \multicolumn{3}{|l|}{$\left[\mathrm{Na}^{+}\right]<120 \mathrm{mEq} / \mathrm{L}$} \\
\hline & & $\begin{array}{l}\text { Evaluable } \\
\text { treatment } \\
\text { episodes, } n\end{array}$ & $\begin{array}{l}\text { Median baseline } \\
{\left[\mathrm{Na}^{+}\right](\mathrm{IQR})} \\
\mathrm{mEq} / \mathrm{L}\end{array}$ & $\begin{array}{l}\text { Median rate of } \\
{\left[\mathrm{Na}^{+}\right] \text {change (IQR), }} \\
\mathrm{mEq} / \mathrm{L} / \text { day }\end{array}$ & $\begin{array}{l}\text { Median } \\
\text { Duration, d }\end{array}$ & $\begin{array}{l}\text { Evaluable treatment } \\
\text { episodes, } n\end{array}$ & $\begin{array}{l}\text { Median }\left[\mathrm{Na}^{+}\right] \\
\text {change (IQR) } \\
\mathrm{mEq} / \mathrm{L} / \text { day }\end{array}$ & $\begin{array}{l}\text { Median } \\
\text { duration, } \\
\text { day }\end{array}$ \\
\hline \multirow[t]{2}{*}{ No active treatment } & Cancer & 41 & $129(4.0)$ & $0.1(0.7)$ & $8.0(9.0)$ & 1 & 1.3 & 9.0 \\
\hline & Non-cancer & 127 & $127(6.0)$ & $0.5(1.0)$ & $7.0(7.0)$ & 7 & $2.3(3.1)$ & $7.0(9.0)$ \\
\hline \multirow[t]{2}{*}{ Fluid restriction } & Cancer & 147 & $125(9.0)$ & $0.8(2.0)$ & $3.0(4.0)$ & 51 & $1.3(2.5)$ & $2.0(4.0)$ \\
\hline & Non-cancer & 601 & $125(8.0)$ & $1.0(2.5)$ & $2.0(4.0)$ & 176 & $1.7(2.2)$ & $3.0(4.0)$ \\
\hline \multirow[t]{2}{*}{ Isotonic saline } & Cancer & 110 & $123(8.0)$ & $1.3(3.0)$ & $1.5(2.0)$ & 29 & $2.0(2.0)$ & $1.0(1.0)$ \\
\hline & Non-cancer & 327 & $125(8.0)$ & $1.5(3.7)$ & $1.0(1.0)$ & 79 & $3.0(5.0)$ & $1.0(1.0)$ \\
\hline \multirow[t]{2}{*}{ Tolvaptan } & Cancer & 67 & $125(8.0)$ & $3.0(4.7)$ & $3.0(4.0)$ & 26 & $3.3(3.9)$ & $2.5(3.0)$ \\
\hline & Non-cancer & 158 & $127(7.0)$ & $3.0(6.0)$ & $2.0(3.0)$ & 32 & $2.2(2.8)$ & $3.0(5.5)$ \\
\hline \multirow[t]{2}{*}{ Salt tablets } & Cancer & 45 & $126(10.0)$ & $0.1(2.0)$ & $2.0(3.0)$ & 13 & $0.8(2.0)$ & $1.0(1.0)$ \\
\hline & Non-cancer & 71 & $128(5.0)$ & $0.8(1.6)$ & $3.0(4.0)$ & 11 & $1.1(2.0)$ & $2.0(2.0)$ \\
\hline \multirow{2}{*}{$\begin{array}{l}\text { Fluid restriction } \\
\quad+\text { isotonic saline }\end{array}$} & Cancer & 50 & $121(9.0)$ & $1.9(3.2)$ & $1.0(1.0)$ & 20 & $2.3(3.0)$ & $1.0(1.0)$ \\
\hline & Non-cancer & 213 & $124(8.0)$ & $2.0(4.0)$ & $1.0(1.0)$ & 59 & $3.5(5.3)$ & $1.0(1.0)$ \\
\hline \multirow[t]{2}{*}{ Hypertonic saline } & Cancer & 18 & $121(10.0)$ & $2.0(7.0)$ & $1.0(1.0)$ & 8 & $8.0(6.4)$ & $1.0(2.0)$ \\
\hline & Non-cancer & 68 & $121(9.5)$ & $3.5(5.8)$ & $2.0(2.0)$ & 28 & $5.8(5.9)$ & $1.0(1.0)$ \\
\hline \multirow[t]{2}{*}{ Demeclocycline } & Cancer & 21 & $128(8.0)$ & $0.0(2.3)$ & $3.0(2.0)$ & 10 & $0.5(3.0)$ & $3.0(2.0)$ \\
\hline & Non-cancer & 31 & $124(8.0)$ & $0.3(2.0)$ & $4.0(4.0)$ & 13 & $0.6(1.7)$ & $3.0(3.0)$ \\
\hline
\end{tabular}

$P$ values $<0.05$ :

Baseline sodium: No active treatment vs. FR, NS, tolvaptan, FR + NS, HS; FR vs. No active treatment, NS, FR + NS, HS; NS vs. No active treatment, FR, salt tabs, demeclocycline; HS vs. No active treatment, FR, tolvaptan, salt tabs, demeclocycline; tolvaptan vs. No active treatment, FR + NS, HS; salt tabs vs. NS, FR + NS, HS; FR + NS vs. No active treatment, FR, tolvaptan, salt tabs, demeclocycline; demeclocycline vs.. NS, HS, FR + NS

Median rate of change: No active treatment vs. FR, NS, tolvaptan, HS, FR + NS; FR vs. No active treatment, NS, tolvaptan, salt tabs, FR + NS, HS, demeclocycline; NS vs. No active treatment, FR, tolvaptan, salt tabs, HS, demeclocycline; tolvaptan vs. No active treatment, FR, NS, salt tabs, FR + NS, demeclocycline; salt tabs vs. FR, NS, tolvaptan, FR + NS, HS, demeclocycline; FR + NS vs. No active treatment, FR, tolvaptan salt tabs, demeclocycline; HS vs. No active treatment, FR, NS, salt tabs, FR + NS, demeclocycline; demeclocycline vs. FR, NS, tolvaptan, salt tabs, FR + NS, HS Duration of therapy: No active treatment vs. FR, NS, tolvaptan, salt tabs, FR + NS, HS, demeclocycline; FR vs. No active treatment, NS, FR + NS, HS; NS vs. No active treatment, FR, tolvaptan, salt tabs, demeclocycline; tolvaptan vs. No active treatment, NS, FR+ NS, HS; Salt Tabs vs. No active treatment, NS, tolvaptan, FR + NS; FR + NS vs. No active treatment, FR, tolvaptan, salt tabs, demeclocycline; HS vs. No active treatment, FR, tolvaptan, demeclocycline; demeclocycline vs. No active treatment, NS, FR + NS, HS

determine if initial therapy containing one of these two highly effective compounds, either as monotherapy or in conjunction with slower acting therapies, was effective in increasing $\left[\mathrm{Na}^{+}\right]$. With a tolvaptan-containing therapy, 59 and $53 \%$ of patients with a starting $\left[\mathrm{Na}^{+}\right]$of $\leq 125 \mathrm{mEq} / \mathrm{L}$ or $<120 \mathrm{mEq} /$ $\mathrm{L}$, respectively, achieved a $\left[\mathrm{Na}^{+}\right]>130 \mathrm{mEq} / \mathrm{L}$, while HScontaining therapies, and the slow-acting treatments, succeeded in only $18 \% / 5 \%$ and $17 \% / 14 \%$, respectively $(P<0.01$, Fig. 2$)$. The time needed to increase $\left[\mathrm{Na}^{+}\right]$to $>130 \mathrm{mEq} / \mathrm{L}$ in the patients who met this goal was 2 days for tolvaptan- and HS-containing treatments, but 4 days for other treatments $(P<0.01)$.

Irrespective of the therapy chosen, the median $\left[\mathrm{Na}^{+}\right]$at discharge in the cancer group (130 (7.0) $\mathrm{mEq} / \mathrm{L})$ was significantly $(P<0.001)$ lower than in the non-cancer group (132 (7.0) $\mathrm{mEq} / \mathrm{L}$ ). Only $46 \%$ of all cancer patients were discharged with $\left[\mathrm{Na}^{+}\right]$above $130 \mathrm{mEq} / \mathrm{L}$ and only $23 \%$ with a normalized $\left[\mathrm{Na}^{+}\right]$. In those discharged with a $\left[\mathrm{Na}^{+}\right] \leq 130 \mathrm{mEq} / \mathrm{L}$ (i.e., the original threshold for inclusion into the Registry), the median $\left[\mathrm{Na}^{+}\right]$was 127 (5) $\mathrm{mEq} / \mathrm{L}$; severe hyponatremia was reported in $6 \%$ and moderate hyponatremia in $32 \%$. Median length of hospital stay was longer $(P<0.001)$ in the cancer group $(9$ vs. 8 days $)$, even after adjusting for hyponatremia correction. With 8.7 vs. $1.9 \%$, in-hospital mortality was significantly $(P<0.001)$ more often reported in the cancer group than in the non-cancergroup; the same was true for referral to hospice (1.9 vs. $0.8 \% ; P<0.001)$.

\section{Discussion}

The Hyponatremia Registry is the largest observational hyponatremia study to date. The current analysis focuses on the subgroup of cancer-related SIADH, which accounts for approximately one third of all cases of SIADH. With 358 patients, this analysis represents the largest group of cancer patients with SIADH ever studied.

Of note, $39 \%$ of all cancer patients initially enrolled as euvolemic hyponatremia had to be excluded, mostly because of clear signs of hypo- or hypervolemia. Thorough assessment of volume status, however, is key for determining the cause of hyponatremia $[15,20]$. Although SIADH is a diagnosis of exclusion, clinicians apparently readily interpret hyponatremia in cancer patients as SIADH without excluding alternative causes. In addition, a minimal set of lab results $[15$, 
Table 3 Achievement of correction benchmarks by therapy episode and overcorrection in the cancer-related and the non-cancer-related SIADH group

\begin{tabular}{|c|c|c|c|c|c|c|c|}
\hline Treatment & & $\begin{array}{l}\Delta\left[\mathrm{Na}^{+}\right] \\
>-2 \mathrm{mEq} / \mathrm{L}(\%)\end{array}$ & $\begin{array}{l}\Delta\left[\mathrm{Na}^{+}\right] \\
+/-2 \mathrm{mEq} / \mathrm{L}(\%)\end{array}$ & $\begin{array}{l}\Delta\left[\mathrm{Na}^{+}\right] \\
\geq 5 \mathrm{mEq} / \mathrm{L}(\%)\end{array}$ & $\begin{array}{l}{\left[\mathrm{Na}^{+}\right]>130} \\
\mathrm{mEq} / \mathrm{L}(\%)\end{array}$ & $\begin{array}{l}{\left[\mathrm{Na}^{+}\right]>135} \\
\mathrm{mEq} / \mathrm{L}(\%)\end{array}$ & $\begin{array}{l}\text { Overly rapid } \\
\text { correction (\%) }\end{array}$ \\
\hline All therapies & $\begin{array}{l}\text { Cancer } \\
\text { Non-cancer }\end{array}$ & $\begin{array}{l}13.9 \\
8.6\end{array}$ & $\begin{array}{l}35.0 \\
32.0\end{array}$ & $\begin{array}{l}38.8 \\
46.7\end{array}$ & $\begin{array}{l}28.0 \\
35.3\end{array}$ & $\begin{array}{l}9.8 \\
13.5\end{array}$ & $\begin{array}{l}11.7 \\
10.1\end{array}$ \\
\hline No active treatment & $\begin{array}{l}\text { Cancer } \\
\text { Non-cancer }\end{array}$ & $\begin{array}{l}17.1 \\
7.0\end{array}$ & $\begin{array}{l}51.2 \\
31.0\end{array}$ & $\begin{array}{l}26.8 \\
44.9\end{array}$ & $\begin{array}{l}36.6 \\
48.0\end{array}$ & $\begin{array}{l}14.6 \\
22.0\end{array}$ & $\begin{array}{l}0.0 \\
3.1\end{array}$ \\
\hline Fluid restriction & $\begin{array}{l}\text { Cancer } \\
\text { Non-cancer }\end{array}$ & $\begin{array}{l}12.0 \\
7.6\end{array}$ & $\begin{array}{l}32.0 \\
30.3\end{array}$ & $\begin{array}{l}35.0 \\
46.3\end{array}$ & $\begin{array}{l}19.7 \\
31.1\end{array}$ & $\begin{array}{l}4.3 \\
10.8\end{array}$ & $\begin{array}{l}2.9 \\
2.5\end{array}$ \\
\hline Isotonic saline & $\begin{array}{l}\text { Cancer } \\
\text { Non-cancer }\end{array}$ & $\begin{array}{l}8.3 \\
8.6\end{array}$ & $\begin{array}{l}38.8 \\
36.2\end{array}$ & $\begin{array}{l}30.7 \\
37.5\end{array}$ & $\begin{array}{l}11.9 \\
22.3\end{array}$ & $\begin{array}{l}1.0 \\
5.7\end{array}$ & $\begin{array}{l}0.8 \\
2.5\end{array}$ \\
\hline Tolvaptan & $\begin{array}{l}\text { Cancer } \\
\text { Non-cancer }\end{array}$ & $\begin{array}{l}2.6 \\
2.9\end{array}$ & $\begin{array}{l}11.5 \\
15.9\end{array}$ & $\begin{array}{l}78.6 \\
78.0\end{array}$ & $\begin{array}{l}73.2 \\
74.8\end{array}$ & $\begin{array}{l}39.3 \\
40.2\end{array}$ & $\begin{array}{l}14.1 \\
11.2\end{array}$ \\
\hline Salt tablets & $\begin{array}{l}\text { Cancer } \\
\text { Non-cancer }\end{array}$ & $\begin{array}{l}13.6 \\
9.6\end{array}$ & $\begin{array}{l}40.7 \\
33.7\end{array}$ & $\begin{array}{l}19.4 \\
38.2\end{array}$ & $\begin{array}{l}25.8 \\
47.3\end{array}$ & $\begin{array}{l}12.9 \\
9.1\end{array}$ & $\begin{array}{l}3.4 \\
0.0\end{array}$ \\
\hline Fluid restriction + isotonic saline & $\begin{array}{l}\text { Cancer } \\
\text { Non-cancer }\end{array}$ & $\begin{array}{l}7.5 \\
6.6\end{array}$ & $\begin{array}{l}43.4 \\
36.1\end{array}$ & $\begin{array}{l}34.0 \\
43.8\end{array}$ & $\begin{array}{l}23.4 \\
24.7\end{array}$ & $\begin{array}{l}6.4 \\
8.2\end{array}$ & $\begin{array}{l}1.9 \\
2.6\end{array}$ \\
\hline Hypertonic saline & $\begin{array}{l}\text { Cancer } \\
\text { Non-cancer }\end{array}$ & $\begin{array}{l}0.0 \\
5.7\end{array}$ & $\begin{array}{l}31.6 \\
24.3\end{array}$ & $\begin{array}{l}41.2 \\
65.6\end{array}$ & $\begin{array}{l}11.8 \\
29.5\end{array}$ & $\begin{array}{l}0.0 \\
16.4\end{array}$ & $\begin{array}{l}15.8 \\
17.1\end{array}$ \\
\hline Demeclocycline & $\begin{array}{l}\text { Cancer } \\
\text { Non-cancer }\end{array}$ & $\begin{array}{l}29.6 \\
4.3\end{array}$ & $\begin{array}{l}22.2 \\
31.9\end{array}$ & $\begin{array}{l}21.4 \\
28.6\end{array}$ & $\begin{array}{l}21.4 \\
17.9\end{array}$ & $\begin{array}{l}0.0 \\
3.6\end{array}$ & $\begin{array}{l}0.0 \\
2.1\end{array}$ \\
\hline
\end{tabular}

Within cancer-related SIADH group:

$P$ values $<0.01$ for

$\Delta[\mathrm{Na}+]>-2 \mathrm{mEq} / \mathrm{L}:$ tolvaptan vs. No treatment, and $\mathrm{ST}$.

$\Delta[\mathrm{Na}+]+/-2 \mathrm{mEq} / \mathrm{L}:$ tolvaptan vs. No treatment, FR, NS, FR + NS, and ST.

$\Delta[\mathrm{Na}+] \geq 5 \mathrm{mEq} / \mathrm{L}$ : tolvaptan vs. No treatment, FR, NS, ST, FR + NS, HS and demeclocycline

$[\mathrm{Na}+]>130 \mathrm{mEq} / \mathrm{L}$ : tolvaptan vs. No treatment, FR, NS, ST, FR + NS, HS and demeclocycline; No treatment vs. NS

$[\mathrm{Na}+]>135 \mathrm{mEq} / \mathrm{L}$ : tolvaptan vs. No treatment $(p=0.012), \mathrm{FR}, \mathrm{NS}, \mathrm{FR}+\mathrm{NS}, \mathrm{HS}$ and demeclocycline. No treatment vs. NS; HS vs. demeclocycline Overly rapid correction: No treatment vs. demeclocycline; tolvaptan vs. FR, NS; HS vs. NS

Cancer vs. non-cancer: $P$ values $<0.01$ for $\Delta[\mathrm{Na}+]>-2 \mathrm{mEq} / \mathrm{L}, \Delta[\mathrm{Na}+] \geq 5 \mathrm{mEq} / \mathrm{L},[\mathrm{Na}+]>130 \mathrm{mEq} / \mathrm{L}$

$19,21]$ is mandatory for a diagnosis of SIADH, but was performed in only $46 \%$ and a hyponatremia expert was consulted in only $43 \%$ of patients. In line with these findings, sub-optimal management of hyponatremia in general is widespread, as has been reported repeatedly $[17,22$, 23]. However, in contrast to what we have previously demonstrated in the overall SIADH population [24], proper work-up of hyponatremia was not associated with superior treatment effectiveness in the cancer-related SIADH subgroup.

If the decision was made to treat hyponatremia (which was not the case in $11.5 \%$ ), the most frequently chosen therapies were FR and NS, even in severe cases. Both therapies led to only a modest $\left[\mathrm{Na}^{+}\right]$rise. However, although considered ineffective and thus not recommended for the treatment of SIADH, NS (1.3 (3.0) $\mathrm{mEq} / \mathrm{L} /$ day) was significantly more effective than FR $(0.8(2.0) \mathrm{mEq} / \mathrm{L} /$ day), the recommended first-line SIADH therapy [15, 19]. Of note, the combination of both therapies worked considerably better than either component alone with a median $\left[\mathrm{Na}^{+}\right]$rise of $1.9(3.2) \mathrm{mEq} / \mathrm{L} /$ day. Tolvaptan increased $\left[\mathrm{Na}^{+}\right]$more rapidly $(3.0(4.7) \mathrm{mEq} / \mathrm{L} /$ day) than any other therapy $(P<0.05)$. Two other popular treatment options, salt tablets and demeclocycline, were virtually noneffective or even deleterious. Surprisingly, HS, the classic treatment of severe hyponatremia, was administered in less than $5 \%$ of initial treatments of such cases. However, in that latter group, HS outperformed all other therapies (median $\left[\mathrm{Na}^{+}\right]$rise of $8.0(6.4) \mathrm{mEq} / \mathrm{L} /$ day). Success rates for reaching one of the three effectiveness benchmarks were at least 1.9-fold higher with tolvaptan than with any other therapy $(P<0.02)$. Consistently, the rate for reaching the combined benchmark ineffectiveness or aggravation was more than $50 \%$ lower with tolvaptan than with any other treatment. Of note, the recommended first-line therapy, FR, led to a relevant $\left[\mathrm{Na}^{+}\right]$decrease in $12 \%$. Unacceptably high rates of hyponatremia aggravation were also observed with NS (8\%), ST (14\%), and demeclocycline (30\%). In line with current clinical practice, in which HS is used only as initial treatment but replaced by other therapies once a reasonable $\left[\mathrm{Na}^{+}\right]$increment has been achieved, the rate of reaching a $\left[\mathrm{Na}^{+}\right]$of above 130 or even $135 \mathrm{mEq} / \mathrm{L}$ was low.

All employed therapies except tolvaptan appeared to be less efficacious in the cancer group as compared to the non- 
Fig. 2 Overall success of increasing $[\mathrm{Na}+]$ to $>130 \mathrm{mEq} / \mathrm{L}$ (a) and time to reach a $[\mathrm{Na}+$ ] $>130 \mathrm{mEq} / \mathrm{L}$ ( $p$ value $<0.05$ : tolvaptan vs. slow-acting therapies, hypertonic saline for both $\leq 125$ and $<120$ ). b With initial therapies containing either tolvaptan or HS, or initial therapies containing less active (LA) therapies: demeclocycline, FR, NS, or salt tablets singly or in combination but not tolvaptan, HS

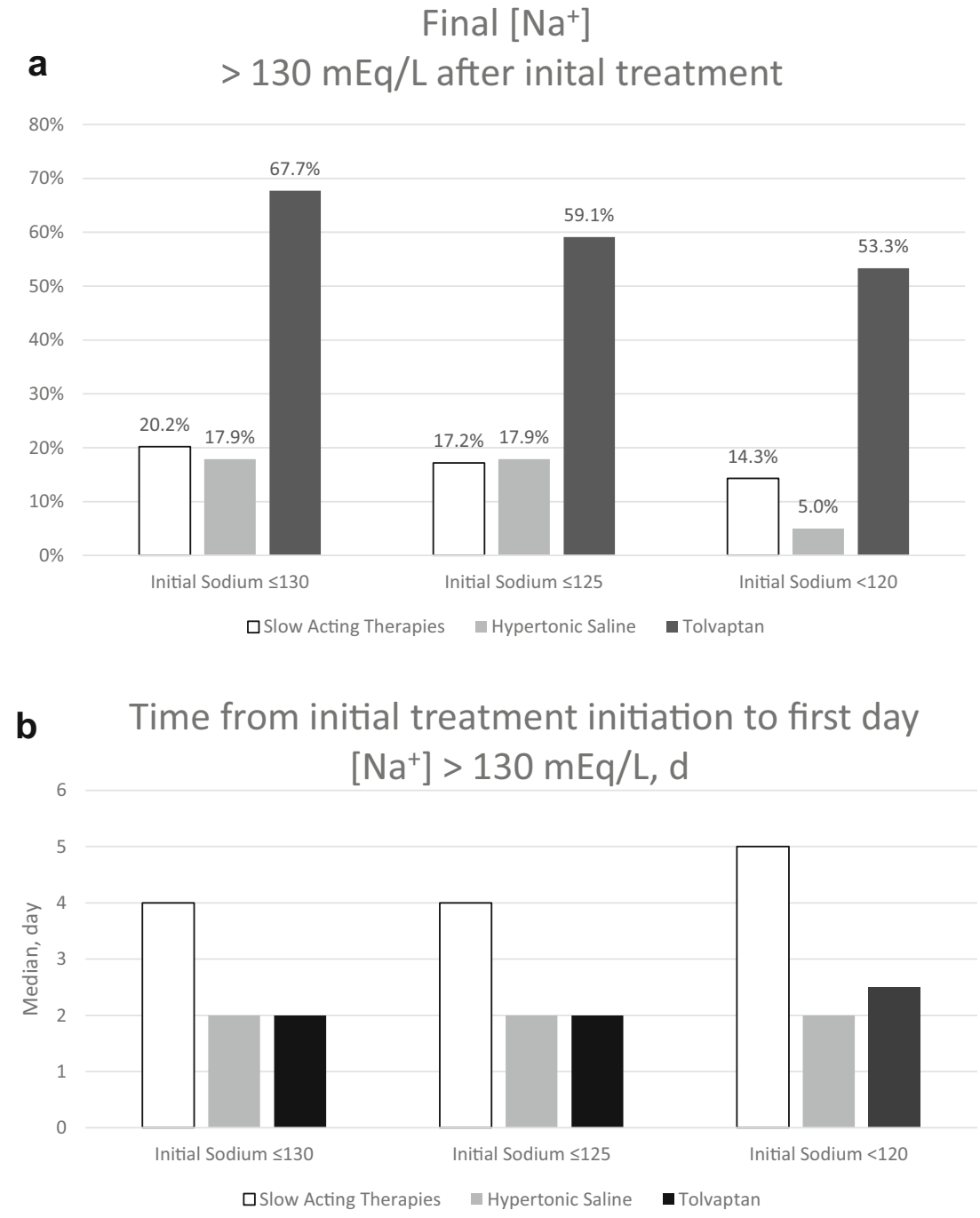

cancer group. Two major reasons may account for this. Firstly, SIADH may be transient and a spontaneous improvement in hyponatremia would be credited in our analysis to any simultaneously administered hyponatremia treatment. Hyponatremia secondary to cancer is less likely to be transient in the short-term. Secondly, it is well known that the effectiveness of the most frequently used therapy, FR, is reduced with higher urine osmolality $[14,20,25]$; the median urine osmolality was significantly higher $(P<0.001)$ in the cancer group (440 $\mathrm{mOsm} / \mathrm{kg} \mathrm{H} \mathrm{H}_{2} \mathrm{O}$ ) than in the non-cancer group (390 $\mathrm{mOsm} / \mathrm{kg} \mathrm{H}_{2} \mathrm{O}$ ). Furthermore, NS is also known to be ineffective or counterproductive in SIADH and worsening of hyponatremia is expected with higher urine osmolality [26]. In contrast, the predicted effect of a pharmacological approach that blocks the vasopressin effect is largely independent of baseline urine osmolality.

Consistent with what has been previously published, our data indicate that treatment response is more pronounced with lower baseline $\left[\mathrm{Na}^{+}\right]$values, irrespective of the employed therapy [24]. This should be taken into consideration when choosing a treatment in patients with moderate/severe hyponatremia.

Since hyponatremia hampers anti-tumor therapy, affects quality of life, interferes with treatment, and often leads to unwanted hospital admissions or prolonged hospital stays, rapid control of $\left[\mathrm{Na}^{+}\right]$is desirable. The rate of reaching a safe $\left[\mathrm{Na}^{+}\right]$level in patients with clinically relevant hyponatremia $\left(\left[\mathrm{Na}^{+}\right] \leq 125 \mathrm{mEq} / \mathrm{L}\right)$ was 3 times as high if the initial therapy contained tolvaptan than with treatments containing only slower-acting therapies or HS-containing therapies. The time needed to reach a $\left[\mathrm{Na}^{+}\right]>130 \mathrm{mEq} / \mathrm{L}$ was significantly shorter (2 days) with a tolvaptan-containing therapy than with less effective therapies ( 4 days) $(P<0.01)$.

The price of high effectiveness is an increased rate of overcorrection with the highly active therapies, tolvaptan (14\%) and HS (16\%). Although there were no cases of osmotic demyelination reported in the registry, this clearly indicates that these therapies must be used with caution. In most cases of overcorrection that occurred with tolvaptan, other therapies 
had been employed concomitantly. Although it is contraindicated to combine either tolvaptan or HS with other therapies, results from the present study indicate that combination therapies containing these compounds are chosen frequently by clinicians.

Two vaptans, tolvaptan and conivaptan, have received approval for treatment of SIADH. In this Registry, only two SIADH patients were treated with conivaptan. Due to differences in route of administration and dosing schedule, we did not pool the data for these two compounds. However, it appears likely that the effectiveness of both vaptans is similar. No safety issues were reported with the use of vaptans in this registry.

The Hyponatremia Registry has a number of limitations, most of which derive from its observational design [18]. Although patients were subject to adjudication by experts, some uncertainty remains regarding the validity of the diagnosis "cancer-related SIADH." Furthermore, potentially hyponatremia-inducing drugs are highly prevalent and interfere with diagnostic precision. However, since the study's intent was to capture "real-world" practice, this limitation does not detract from observing how clinician-diagnosed SIADH in the oncology setting is managed. As in other hyponatremia trials, numerical changes of $\left[\mathrm{Na}^{+}\right]$were used as the primary measure of effectiveness; neither symptoms nor clinical outcome after therapy were reported routinely as it is extremely difficult to assign these unambiguously to hyponatremia, especially in the oncology setting.

In summary, despite the high prevalence of hyponatremia $[1-3]$ and published guidance on its diagnosis and treatment $[11,15,19,20]$, numerous shortcomings in current management of hyponatremia in cancer-related SIADH are evident. Hyponatremia in a cancer patient is readily assumed by clinicians to be due to SIADH without sufficient attention to accepted diagnostic criteria. Moreover, many patients correctly diagnosed with SIADH do not receive any treatment for hyponatremia at all, and a considerable number of patients are discharged with unresolved hyponatremia. FR and NS are the two most frequently used therapies but are ineffective in about two thirds of cases. Of note, this lack of efficacy is more pronounced in cancer patients than in non-cancer-related SIADH. With the vaptans, a group of highly effective and yet safe compounds is available and the findings of this analysis strongly suggests that they should be viewed as first-line choice of treatment. However, they are only used in the minority of cases in current practice. We therefore conclude that there is a need to focus educational efforts on (1) how to diagnose SIADH correctly, (2) the lack of uniform efficacy of FR and NS, (3) the use of active treatments, and (4) increasing awareness of risk factors for overcorrection. Despite clear evidence that hyponatremia is associated with poor prognosis in particular in cancer patients, proof of causation is still lacking. Future research efforts should, therefore, focus on which cancer patients will benefit most from correction of hyponatremia.
Acknowledgments We thank Alpesh Amin, MD; Jun Chiong, MD; Joseph Dasta, PharmD; Paul Hauptman, MD; and Samuel Sigal, MD, for their participation on the US Steering Committee for the Hyponatremia Registry, with funding by Otsuka. We thank Stephen Ball, MBBS, PhD, FRCP, Newcastle University, Newcastle, UK; JeanPhilippe Haymann, MD, Hôpital Tenon, Paris, France; Gudmundur Johannsson, MD, PhD, University of Göteborg, Sweden; Jens Otto Lunde Jørgensen, MD, Aarhus University Hospital, Aarhus, Denmark; Alessandro Peri, MD, University of Florence, Italy; and Esteban Poch, MD, University of Barcelona, Spain, for their participation on the European Steering Committee for the Hyponatremia Registry, with funding by Otsuka. Statistical analysis was performed by the Mapi Group, Lexington, KY, with funding from Otsuka. Jamie Jarecki-Smith of Otsuka provided continuing support for reviewing data entered in preparation for analysis and for accuracy.

\section{Compliance with ethical standards}

Conflict of Interest Author Conflict of Interest Disclosures: Dr. Burst is a consultant and his institution received research support from Otsuka for the Hyponatremia Registry. He received travel support and fees for data review activities, and serves on a speakers' bureau for Otsuka. Dr. Grundmann and her institution received research support from Otsuka for participating in the Hyponatremia Registry and for other clinical research. Her institution also received research support from Alexion, Janssen, AstraZeneca, Chemocentryx, as well as grants from DFG, Koeln Fortune, and non-financial support from Astellas. Dr. Kubacki has received travel support from Otsuka. Dr. Greenberg is a consultant and his institution received research support for the Hyponatremia Registry from Otsuka. He received travel support and fees for data review activities, and serves on a speakers' bureau for Otsuka. He has acted as a consultant for Cornerstone. Dr. Rudolf is an Otsuka employee. Dr. Verbalis is a consultant, and his institution received research support for the Hyponatremia Registry and for investigator-sponsored trials from Otsuka. Dr. Salahudeen was a consultant and his institution received grants from Otsuka for works outside of the submitted manuscript. He has also received travel support from Otsuka. Dr. Grohé is a consultant and his institution received research support from Otsuka for participating in the Hyponatremia Registry and for clinical research. No payment was provided to any author for the development of the manuscript.

Funding/support The academic co-authors take full responsibility for study design, data analysis plan, and drafting of the manuscript. They had unlimited access to the data. Statistical analysis was performed by employees of the TCM Group and Mapi Group. Funding for study design and conduct, statistical analyses, and study oversight was provided by Otsuka America Pharmaceutical, Inc. (OAPI).

Open Access This article is distributed under the terms of the Creative Commons Attribution-NonCommercial 4.0 International License (http:// creativecommons.org/licenses/by-nc/4.0/), which permits any noncommercial use, distribution, and reproduction in any medium, provided you give appropriate credit to the original author(s) and the source, provide a link to the Creative Commons license, and indicate if changes were made.

\section{References}

1. Berghmans T, Paesmans M, Body JJ (2000) A prospective study on hyponatraemia in medical cancer patients: epidemiology, aetiology and differential diagnosis supportive care in cancer. Official journal of the Multinational Association of Supportive Care in Cancer 8: 192-197 
2. Castillo JJ, Vincent M, Justice E (2012) Diagnosis and management of hyponatremia in cancer patients. Oncologist 17:756-765

3. Sorensen JB, Andersen MK, Hansen HH (1995) Syndrome of inappropriate secretion of antidiuretic hormone (SIADH) in malignant disease. J Intern Med 238:97-110

4. Berardi R, Caramanti M, Castagnani M, Guglielmi S, Marcucci F, Savini A, Morgese F, Rinaldi S, Ferrini C, Tiberi M, Torniai M, Rovinelli F, Fiordoliva I, Onofri A, Cascinu S (2015) Hyponatremia is a predictor of hospital length and cost of stay and outcome in cancer patients supportive care in cancer. Official journal of the Multinational Association of Supportive Care in Cancer 23:30953101

5. Berardi R, Caramanti M, Fiordoliva I, Morgese F, Savini A, Rinaldi S, Torniai M, Tiberi M, Ferrini C, Castagnani M, Rovinelli F, Onofri A, Cascinu S (2015) Hyponatraemia is a predictor of clinical outcome for malignant pleural mesothelioma supportive care in cancer. Official journal of the Multinational Association of Supportive Care in Cancer 23:621-626

6. Doshi SM, Shah P, Lei X, Lahoti A, Salahudeen AK (2012) Hyponatremia in hospitalized cancer patients and its impact on clinical outcomes. Am J Kidney Dis 59:222-228

7. Hansen O, Sorensen P, Hansen KH (2010) The occurrence of hyponatremia in SCLC and the influence on prognosis: a retrospective study of 453 patients treated in a single institution in a 10-year period. Lung Cancer 68:111-114

8. Jeppesen AN, Jensen HK, Donskov F, Marcussen N, von der Maase $\mathrm{H}$ (2010) Hyponatremia as a prognostic and predictive factor in metastatic renal cell carcinoma. Br J Cancer 102:867-872

9. Petereit C, Zaba O, Teber I, Grohe C (2011) Is hyponatremia a prognostic marker of survival for lung cancer? Pneumologie 65: 565-571

10. Schutz FA, Xie W, Donskov F, Sircar M, McDermott DF, Rini BI, Agarwal N, Pal SK, Srinivas S, Kollmannsberger C, North SA, Wood LA, Vaishampayan U, Tan MH, Mackenzie MJ, Lee JL, Rha SY, Yuasa T, Heng DY, Choueiri TK (2014) The impact of low serum sodium on treatment outcome of targeted therapy in metastatic renal cell carcinoma: results from the International Metastatic Renal Cell Cancer Database Consortium. Eur Urol 65: 723-730

11. Grohe C, Berardi R, Burst V (2015) Hyponatraemia-SIADH in lung cancer diagnostic and treatment algorithms. Crit Rev Oncol Hematol 96:1-8

12. Berardi R, Santoni M, Rinaldi S, Nunzi E, Smerilli A, Caramanti M, Morgese F, Torniai M, Savini A, Fiordoliva I, Onofri A, Pistelli M, Taccaliti A, Cascinu S (2016) Risk of hyponatraemia in cancer patients treated with targeted therapies: a systematic review and meta-analysis of clinical trials. PLoS One 11:e0152079
13. Adrogue HJ, Madias NE (2012) The challenge of hyponatremia. J Am Soc Nephrol 23:1140-1148

14. Ellison DH, Berl T (2007) Clinical practice. The syndrome of inappropriate antidiuresis. N Eng1 J Med 356:2064-2072

15. Verbalis JG, Goldsmith SR, Greenberg A, Korzelius C, Schrier RW, Sterns RH, Thompson CJ (2013) Diagnosis, evaluation, and treatment of hyponatremia: expert panel recommendations. Am J Med 126:S1-42

16. Berardi R, Rinaldi S, Caramanti M, Grohe C, Santoni M, Morgese F, Torniai M, Savini A, Fiordoliva I, Cascinu S (2016) Hyponatremia in cancer patients: time for a new approach. Crit Rev Oncol Hematol 102:15-25

17. Greenberg A, Verbalis JG, Amin AN, Burst VR, Chiodo JA 3rd, Chiong JR, Dasta JF, Friend KE, Hauptman PJ, Peri A, Sigal SH (2015) Current treatment practice and outcomes. Report of the hyponatremia registry. Kidney Int 88:167-177

18. Hauptman PJ, Greenberg A, Verbalis JG, Amin A, Sigal SH, Chiong J (2013) Design of a prospective, multinational registry to evaluate patients hospitalized with hyponatremia: the HN Registry. Open Access J Clin Trials 5:93-100

19. Spasovski G, Vanholder R, Allolio B, Annane D, Ball S, Bichet D, Decaux G, Fenske W, Hoorn EJ, Ichai C, Joannidis M, Soupart A, Zietse R, Haller M, van der Veer S, Van Biesen W, Nagler E, Hyponatraemia Guideline Development G (2014) Clinical practice guideline on diagnosis and treatment of hyponatraemia. Nephrol Dial Transplant 29(Suppl 2):i1-i39

20. Adrogue HJ, Madias NE (2000) Hyponatremia. N Engl J Med 342: 1581-1589

21. Bartter FC, Schwartz WB (1967) The syndrome of inappropriate secretion of antidiuretic hormone. Am J Med 42:790-806

22. Clayton JA, Le Jeune IR, Hall IP (2006) Severe hyponatraemia in medical in-patients: aetiology, assessment and outcome. QJM 99: 505-511

23. Huda MS, Boyd A, Skagen K, Wile D, van Heyningen C, Watson I, Wong S, Gill G (2006) Investigation and management of severe hyponatraemia in a hospital setting. Postgrad Med J 82:216-219

24. Verbalis JG, Greenberg A, Burst V, Haymann JP, Johannsson G, Peri A, Poch E, Chiodo JA 3rd, Dave J (2016) Diagnosing and treating the syndrome of inappropriate antidiuretic hormone secretion. Am J Med 129(537):e539-e537 e523

25. Furst H, Hallows KR, Post J, Chen S, Kotzker W, Goldfarb S, Ziyadeh FN, Neilson EG (2000) The urine/plasma electrolyte ratio: a predictive guide to water restriction. Am J Med Sci 319:240-244

26. Schwartz WB, Bennett W, Curelop S, Bartter FC (1957) A syndrome of renal sodium loss and hyponatremia probably resulting from inappropriate secretion of antidiuretic hormone. Am J Med 23:529-542 